International Journal of Current Advanced Research

ISSN: O: 2319-6475, ISSN: P: 2319 - 6505, Impact Factor: SJIF: 5.995

Available Online at www.journalijcar.org

Volume 6; Issue 4; April 2017; Page No. 3474-3477

DOI: http://dx.doi.org/10.24327/ijcar.2017.3477.0297

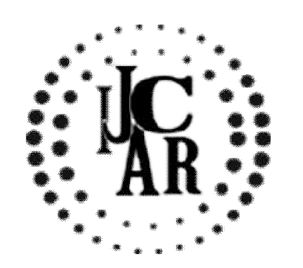

Research Article

\title{
SUICIDE ATTEMPT: SOCIO-DEMOGRAPHIC/MOTIVATIONAL DESCRIPTION OF CASE SERIES IN SANTA ROSA, GUATEMALA
}

\section{Mabby Dariana Franco Mijangos ${ }^{1}$., Lourdes Nineth Calijau Coguox ${ }^{2}$., Mario Rodolfo Salazar Morales ${ }^{3}$., Donovan Casas Patiño ${ }^{4}$ and Alejandra Rodríguez Torres 4,5}

\author{
${ }^{1}$ Resident of the Master's in Hospital Administration and Maintenance, USAC, Guatemala \\ 2 Resident of the Master's in Internal Medicine, USAC, Guatemala \\ ${ }^{3}$ Coordinator of the Doctorate in Public Health, Faculty of Medical Sciences, USAC, Guatemala. \\ ${ }^{4}$ University Autonomous State of Mexico, Amecameca University Center. \\ ${ }^{5}$ Family Medicine Unit 73 Mexican Social Security Institute, Amecameca.
}

\begin{tabular}{l}
\hline A R T I C L E I N F O \\
Article History: \\
Received $14^{\text {th }}$ January, 2017 \\
Received in revised form $10^{\text {th }}$ February, 2017 \\
Accepted $22^{\text {nd }}$ March, 2017 \\
Published online $28^{\text {th }}$ April, 2017
\end{tabular}

Key words:

Suicide attempt, Suicide,

Depression, Anxiety.

\begin{abstract}
A B S T R A C T
Introduction: The objective of the article is to describe the epidemiological and motivational characteristics, as well as the levels of anxiety-depression of the cases with suicidal intent, that received attention in the Regional Hospital of Cuilapa, Santa Rosa, Guatemala.

Methods: Descriptive cross-sectional study. We interviewed all the people who tried to commit suicide in a period of 60 days, to identify their epidemiological and motivational characteristics, and the Hamilton test was applied for the search of levels of depression and anxiety.

Results: The following sociodemographic profile was detected: $58 \%$ women, $39 \%$ between 14 and 18 years old, followed by 39 to 43 years old with $16 \%, 45 \%$ did not profess any religion, $55 \%$ Singles, $65 \%$ working in agriculture and housewives. Seventy-one percent used poisoning as the main motive, with $84 \%$ of couples and relatives reported as the main reason. All cases showed anxiety and depression.

Conclusion: The sociodemographic characteristics of this study share some similarities with international references but at the same time have some particular characteristics that are important to consider in order to prevent this complex psycho-social problem. Information campaigns are required, but it's necessary a multidisciplinary team triangulated with the patient and the family in order to avoid further suicide attempts or the culmination of suicide.
\end{abstract}

Copyright@2017 Mabby Dariana Franco Mijangos et al. This is an open access article distributed under the Creative Commons Attribution License, which permits unrestricted use, distribution, and reproduction in any medium, provided the original work is properly cited.

\section{INTRODUCTION}

The suicide attempt defined by the World Health Organization as a non-habitual act, with a non-lethal result, deliberately initiated and performed by the subject, to cause self-injury or to determine it without the intention of others, or also to cause it by ingestion of drugs in doses higher than that recognized as therapeutic ${ }^{1,2}$. It is among the first three causes of death among people aged 15-44 years ${ }^{3}$ and is $10-20$ times more frequent than suicide itself ${ }^{4}$. The suicide mortality coefficient (number of suicides per 100,000 inhabitants) is higher in Eastern European countries, at intermediate level are the United States, Central Australia, Japan and Central European countries; finally, the countries with the lowest coefficient are those of Central America and South America.

*Corresponding author: Mabby Dariana Franco Mijangos Resident of the Master's in Hospital Administration and Maintenance, USAC, Guatemala
That suicide attempts exceed the number of suicides, there is no national record of such attempts, and suicide attempt is a risk factor for its future concretion, raising the risk up to 100 times compared to the general population ${ }^{6}$. In Guatemala, the attempted suicide rate for 2012 was 8.7 per 100,000 people, according to the Pan American Health Organization ${ }^{7}$, with pesticide intake, hanging, and use of firearms being the most frequent forms. There are more cases of suicide in men than in women, but women try it more often than $\operatorname{men}^{7,8,9}$, with fewer fatal outcomes. Guatemala is divided into 21 departments, and the highest incidence of suicide is found in the following departments: Quiché, Huehuetenango, Escuintla, Santa Rosa, Retalhuleu, Sololá and Quetzaltenango $^{10}$. According to data from the National Civil Police of Guatemala, in 2014 suicides showed the highest incidence in Santa Rosa, ranking first in the departmental level with 32 cases, of which $56 \%$ were between the ages of 12 to 25 years ${ }^{11}$.In Guatemala there is a sub-registry in relation to the suicide attempts since they are not part of the 
protocols of epidemiological surveillance. This phenomenon has in itself a particular epidemiology, since it has a frequency and characteristics of complex presentation, this makes it comparable to public health problems of the nature of communicable diseases and chronic degenerative diseases. Currently in Guatemala there are no protocols for follow-up of cases and comprehensive social prevention of this disorder, as it is not considered a health problem, leaving it alone as a social problem. The study of this event is important, because the department of Santa Rosa is affected by this type of conflicts and it is placed in the first places at national level by suicides. At the Regional Hospital of Cuilapa cases of suicide attempt are attended and an increase in the number of attentions has been observed, so it was relevant to investigate as an epidemiological phenomenon but at the same time to investigate the motivational reasons related to be able to perform an intervention not only Under the biomedical view but to alert about the attention of a complex psychosocial phenomenon and to be able to give preventive measures to that level.

\section{MATERIALS AND METHODS}

Descriptive cross-sectional study of a series of suicideattempted cases treated at the emergency service of the Regional Hospital of Cuilapa, Santa Rosa, Guatemala, in the period of June to August of 2016. Respecting the care of the attending medical personnel and the situation of the companions, prior informed consent, the study interviews were applied in relation to general data and identification as well as the causes that motivated the suicide attempt, in addition the Hamilton test was applied to determine depression and anxiety in each case.

\section{RESULTS}

Thirty-one cases of suicide attempt were detected, of which $18(58 \%)$ were women and $13(42 \%)$ were men. In terms of age, $39 \%$ of the cases were 14 to 18 years old and $16 \%$ were between 39 and 43 years old. Related to religion 45\% (14 cases) professed none while $29 \%$ were Catholic. According to the civil status $55 \%$ were single and 10 married. According to the occupation (32\%) were farmers, 32\% housewives and $23 \%$ students. $84 \%$ were from Santa Rosa, being the municipalities with the greatest number of cases: Barberena, Cuilapa and Nueva Santa. 52\% had primary education, 26\% had secondary education, and 10\% (Table 1).

Among the methods used as a suicide attempt, 71\% used poisoning with agrochemicals such as pesticides and herbicides, secondly drug overdose and lastly the use of a puncture weapon. As the main motive for attempting suicide, we found the couple problems as well as the family problems (Table 2).

All the people interviewed showed a degree of depression and anxiety according to the Hamilton instrument, the women had very severe depression in a greater percentage compared to the men as well as greater anxiety (graphs 1 and 2).

Table 1 Epidemiological characteristics of people treated at the Regional Hospital of Cuilapa, Santa Rosa, by sex, June-August 2016

\begin{tabular}{|c|c|c|c|c|c|c|}
\hline & \multicolumn{2}{|c|}{ Female } & \multicolumn{2}{|c|}{ Male } & \multicolumn{2}{|c|}{ Total } \\
\hline & $\mathbf{F}$ & $\%$ & $\mathbf{F}$ & $\%$ & $\mathbf{F}$ & $\%$ \\
\hline \multicolumn{7}{|l|}{ Sex } \\
\hline Female & \multirow[b]{2}{*}{--- } & \multirow[b]{2}{*}{--- } & \multirow{2}{*}{--- } & \multirow{2}{*}{--} & 18 & 58.06 \\
\hline Male & & & & & 13 & 41.94 \\
\hline \multicolumn{7}{|l|}{ Age } \\
\hline $14-18$ & 9 & 50.00 & 3 & 23.08 & 12 & 38.71 \\
\hline $19-23$ & 3 & 16.67 & 1 & 7.69 & 4 & 12.90 \\
\hline $24-28$ & 1 & 5.57 & 3 & 23.08 & 4 & 12.90 \\
\hline $39-43$ & 1 & 5.57 & 4 & 30.77 & 5 & 16.13 \\
\hline \multicolumn{7}{|l|}{ Religion } \\
\hline No one & 7 & 38.89 & 7 & 53.84 & 14 & 45.16 \\
\hline Catolic & 5 & 27.78 & 4 & 30.77 & 9 & 29.03 \\
\hline Protestant & 5 & 27.78 & 2 & 15.38 & 7 & 22.58 \\
\hline \multicolumn{7}{|l|}{ Civil Status } \\
\hline Unmarried & 12 & 66.66 & 5 & 38.47 & 17 & 54.84 \\
\hline United & 3 & 16.67 & 7 & 53.84 & 10 & 32.26 \\
\hline Married & 3 & 16.67 & 1 & 7.69 & 4 & 12.90 \\
\hline \multicolumn{7}{|l|}{ Occupation } \\
\hline Housewife & 10 & 55.55 & 0 & 0.00 & 10 & 32.26 \\
\hline Farmer & 0 & 0.00 & 10 & 76.92 & 10 & 32.26 \\
\hline Student & 6 & 33.33 & 1 & 7.69 & 7 & 22.58 \\
\hline \multicolumn{7}{|l|}{ Department } \\
\hline Santa Rosa & 15 & 83.33 & 11 & 84.61 & 26 & 83.87 \\
\hline Jutiapa & 2 & 11.11 & 1 & 7.69 & 3 & 9.68 \\
\hline Guatemala & 1 & 5.55 & 1 & 7.69 & 2 & 6.45 \\
\hline \multicolumn{7}{|l|}{ Municipality } \\
\hline Barberena & 2 & 11.11 & 2 & 15.38 & 4 & 12.9 \\
\hline Cuilapa & 4 & 22.22 & 0 & 0.00 & 4 & 12.9 \\
\hline Nueva Santa Rosa & 2 & 11.11 & 2 & 15.38 & 4 & 12.9 \\
\hline \multicolumn{7}{|l|}{ Scholarship } \\
\hline Primary & 7 & 38.89 & 9 & 69.23 & 16 & 51.61 \\
\hline Basic & 6 & 33.33 & 2 & 15.38 & 8 & 25.81 \\
\hline Diversified & 2 & 11.11 & 1 & 7.69 & 3 & 9.68 \\
\hline Any & 2 & 11.11 & 1 & 7.69 & 3 & 9.68 \\
\hline
\end{tabular}

Source: Own by the authors 
Table 2 Motivational causes of people attended by attempted suicide at the Regional Hospital of Cuilapa, Santa Rosa, by sex, June-August 2016

\begin{tabular}{cccccccc}
\hline & \multicolumn{2}{c}{ Female } & \multicolumn{2}{c}{ Male } & \multicolumn{2}{c}{ Total } \\
\hline & f & \% & f & \% & F & $\%$ \\
\hline Method Used & & & & & & \\
\hline Poisoning & 11 & 61.11 & 11 & 84.61 & 22 & 70.97 \\
Overdose & & & & & & \\
Drug & 6 & 27.77 & 1 & 7.69 & 6 & 19.35 \\
Sharp weapon & 2 & 11.11 & 0 & 0 & 2 & 6.45 \\
\hline Reason for attempting & & & & & & \\
\hline Partner problem & 9 & 50 & 4 & 30.77 & 13 & 41.94 \\
Family problem & 7 & 38.88 & 6 & 46.15 & 13 & 41.94 \\
Financial problem & 0 & 0 & 2 & 15.38 & 2 & 6.45 \\
\hline
\end{tabular}

Source: Own by the authors

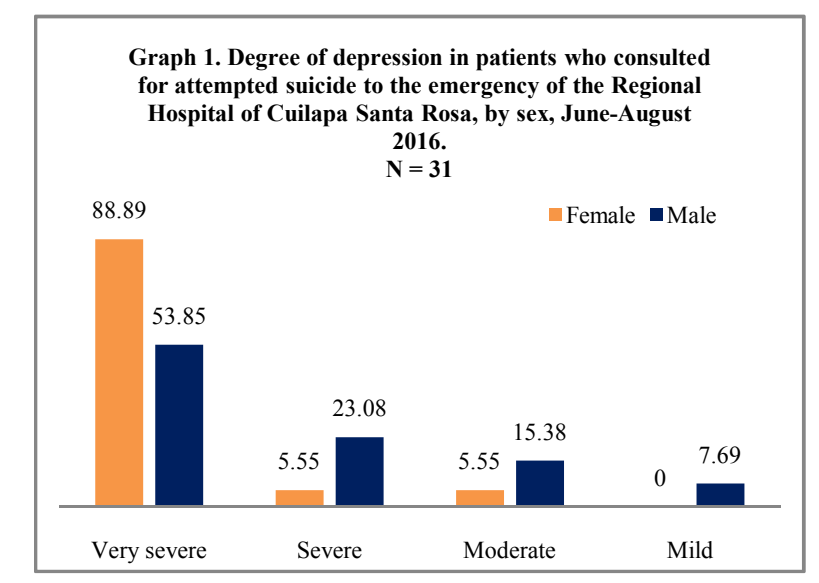

Source: Own by the authors

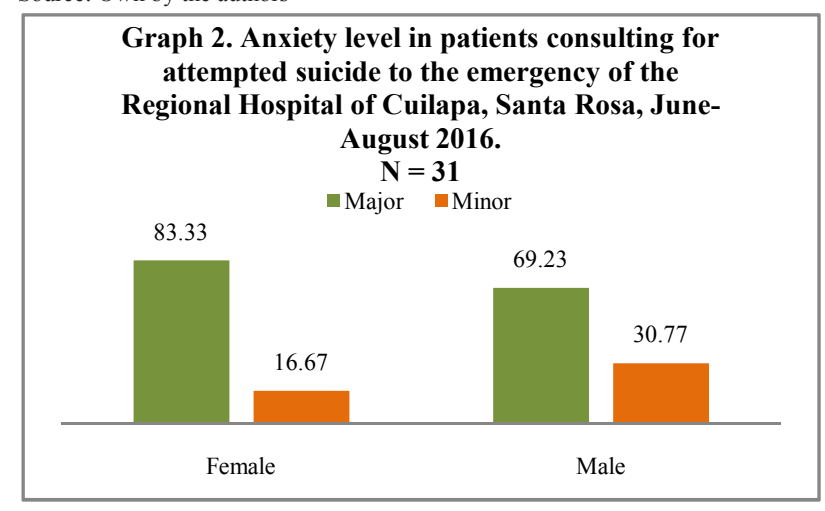

Source: Own by the authors

\section{DISCUSSION}

In 201432 deaths from suicide were reported in Santa Rosa. In the study period, 31 cases of suicide attempt were reported in the hospital of Cuilapa, with 12 cases ending in deaths, reflecting that this problem is on the rise. 58\% are women, which coincides with theoretical references that women try to commit suicide more than men ${ }^{1.3}$. The most frequent ages are 14 and 18 years, half of the women belong to this age range; In second place is the age group of 39 and 43 years with male predominance. The figures are comparable with the world's most frequent ages ranging from 15 to 29 years ${ }^{1}$.

Nearly half of the cases do not profess any religion and the other half, most of them are Catholics followed by Protestants, this differs with references that reveal suicides among the Catholic community less frequently than in Protestant people ${ }^{3}$.
In relation to marital status, singleton predominates in more than half of cases, highlighting in the female sex and it should be noted that the majority of cases were treated as minors. It has been studied that being married reduces risk significantly, so singleton is classified as a risk factor ${ }^{3}$. It is also noteworthy that a significant percentage identified as main problems the relationship with the mother which, like other studies, shows the direct relationship between family dynamics and suicidal behavior $^{12,13}$.

The most common occupations were housewife for women and farmer for men, which differs from other studies which indicate that the higher a person's social level, the greater the risk of suicide ${ }^{14}$. In relation to the level of schooling, half of the cases had primary school instruction and only a quarter with secondary education. This draws attention to and remains to future investigations as to whether there was a history of poor performance at school because the latter has been related to school misconduct and to a greater suicide attempt ${ }^{15}$. The origin of the cases is based in the department of Santa Rosa in its entirety, having visited the hospital in Cuilapa for being the center of attention of the head. The municipalities with more cases, therefore with more vulnerability are Cuilapa, Barberena and Nueva Santa Rosa.

As the most used methods as a suicide attempt was poisoning with herbicides and organophosphates as the main economic activity is agriculture and these products are accessible and there is no regulation for sale, men being the most used this method and women use More drugs, which is a less traumatic but with important sequelae. Depression and anxiety were present in all cases, which has been widely studied as an important risk factor for attempted suicide or suicide in general. ${ }^{15}$

\section{CONCLUSION}

It was observed that the suicide attempts attended in Cuilapa hospital have been presented more in: young women, single, with low schooling, without a religious identification, by family or sentimental problems, with depression and anxiety, silent, and used poisoning With agrochemicals and drug overdose. They carry a high social cost, added to the economic cost represented by the loss of young lives, expenditure of hospital supplies that are scarce and time of care employed without positive results in the event's fatality. For this reason, it is recommended that information and awareness campaigns be carried out in educational institutions, health posts and health centers about suicide, training health and education personnel to detect early signs of depression and anxiety. But above all, having a multidisciplinary team that not only cares for the patient but also the relatives in order to form a triangulation of care prevention and care to avoid new attempts or to commit suicide.

\section{Acknowledgments}

To the Regional Hospital of Cuilapa, Santa Rosa, for allowing us to carry out the study, to the physicians of the hospital: Miguel Eduardo García and Edgar René Peña García, for the support to the realization of the field investigation. 


\section{Bibliography}

1. Organización Mundial de la Salud (OMS). Centro de prensa: Suicidio. Recuperado de: http://www.who.int/ mediacentre/factsheets/fs398/es/

2. Ministerio de sanidad, política social e igualdad. Guía de Práctica Clínica de Prevención y Tratamiento de la Conducta Suicida.2012. Recuperado de: http://www.guiasalud.es/GPC/GPC_481_Conducta_Su icida_Avaliat_compl.pdf

3. Botega J. Comportamento suicida: epidemiologia. Psicologia USP (2014): 231-236.

4. Silva L. Intento de suicidio. En: Guías para manejo de urgencias. 3 ed. Bogotá: Ministerio de la Protección Social/FEPAFEM; 2009. Recuperado de: http://www.aibarra.org/apuntes/criticos/Guías/Psiquiatr ia/Intento_de_suicidio.pdf

5. World Health Organization. Global Health Observatory (GHO) data.http://www.who.int/gho/mental health/ suicide rates crude/en/

6. Gutierrez O, Aparecida B. Assistência hospitalar na tentativa de suicidio. Psicologia USP,2014, 25(3): 262-269

7. Organización Panamericana de la Salud. Enfermedades transmisibles y de salud mental. Washington, D.C.: OPS; 2014. Prevención del suicidio: un imperativo global.p.p7-23,83. Recuperado de: http:// apps. who.int/iris/bitstream/10665/136083/1/9789275318508 spa.pdf.

8. Organización Panamericana de la Salud. Informe sub regional de suicidio en Centroamérica y República Dominicana, 1988-2008. Nicaragua: OPS; 2011 (informe subregional). Recuperado de: http: //new.paho.org/hq/dmdocuments/OPS\%20Suicidio\%20 en $\% 20 \mathrm{CA} \% 20 y \% 20$ RD.pdf. ISBN 978-9962-642-572 .

How to cite this article:

Mabby Dariana Franco Mijangos et al (2017) ' Suicide Attempt: Socio-Demographic/Motivational Description Of Case Series In Santa Rosa, Guatemala', International Journal of Current Advanced Research, 06(04), pp. 3474-3477.

DOI: http://dx.doi.org/10.24327/ijcar.2017.3477.0297
9. Sarró M, Tejedor C, Albeerto M, Arranz M, Boatas F, Cañete J. et al. Suicidio y autolesiones. En: Comité de consenso de Catalunya en terapéutica de los trastornos mentales, editor. RTM-III: Recomendaciones terapéuticas en los trastornos mentales. 3 ed. España: Ars Medica; 2005. pp 2-17. Recuperado de: http://www.suicidioprevencion.com/pdf/RTM3.pdf

10. Alvizurez Y. Van 26 suicidios en 7 departamentos. Prensa Libre. 8 Mar 2016: Departamental: 20.

11. Dirección General de la Policía Nacional Civil. Ministerio de Gobernación. Guatemala. Observaciones no publicadas, 2016.

12. Xing XY, Tao FB, Hao JH, et al. Family factors associated with suicide attempts among chinese adolescent students: a nacional cross-sectional survey. Journal of Adolescent Health 2010; 46: 592599.

13. Evans E, Hawton K, Rodham K, Deeks J. The prevalence of suicidal phenomena in adolescents: a systematic review of population-based studies suicide life threat. Behav. 2005; 35(3): 239-50.

14. Sadock BJ, Sadock VA. Kaplan y Sadock sinopsis de psiquiatría. 10 ed. España: Wolters Kluwe/ Lippincott, Williams \& Wilkins; 2009. Capítulo 34. Medicina psiquiátrica de urgencias. Suicidio. p.897-901.

15. Vargas, Horacio B.; Saavedra, Javier E. Factores asociados con la conducta suicida en adolescentes Revista de Neuro-Psiquiatría, vol. 75, núm. 1, 2012, pp. 19-28. 